\title{
Wettability alteration and enhanced gas condensate recovery by treatment of carbonate reservoir rock using supercritical R134A and R404A gases
}

\author{
Iman Nowrouzi ${ }^{1}$. Abbas Khaksar Manshad ${ }^{2,3} \cdot$ Amir H. Mohammadi $^{1}$ (i)
}

Received: 18 March 2020 / Accepted: 11 September 2020 / Published online: 27 September 2020

(c) The Author(s) 2020

\begin{abstract}
The pressure drop around the well in the production from a gas condensate reservoir causes the formation of condensate in the area before it reaches the well and surface space. This condensate and occasionally water in the porous medium can block the well and create an additional pressure drop. Studies show that the chemical treatment of this area eliminates the problem by altering the reservoir rock wettability toward a moderate and strong gasphilicity. For this purpose, fluoropolymers-, fluorosurfactants-, and fluorochemicals-coated nanoparticles can be used. In this work, we have studied two types of fluoride gas namely R134A and R404A, which are widely used in refrigeration industry as refrigerant gases, perfumery, and industrial detergents. The basis of this study was the aging of rock samples in thin sections and plugs in these two gases at different pressures above the critical pressures of them at $70^{\circ} \mathrm{C}$ at different times and then conducting the contact angle experiments by placing the drop of water and condensate on the cross sections and then performing imbibition tests using plugs. The results show that in addition to the efficiency of both gases in wettability alteration to gasphilic, the gasphilic intensity obtained at constant temperature depends on the pressure and the aging time of the samples.
\end{abstract}

Keywords Gas condensate $\cdot$ Liquid blockage $\cdot$ R134A $\cdot$ R404A $\cdot$ Gasphilicity $\cdot$ Wettability

\section{Introduction}

Reservoirs with temperatures between the critical temperature and the maximum reservoir temperature are a unique type of hydrocarbon accumulation known as gas condensate reservoirs. In these reservoirs, the process of condensate production is based on certain thermodynamic behavior, in which the reverse behavior occurs by decreasing the pressure, rather than expanding the gas or liquid evaporation

Abbas Khaksar Manshad

khaksar@put.ac.ir

$\triangle$ Amir H. Mohammadi amir_h_mohammadi@yahoo.com

1 Discipline of Chemical Engineering, School of Engineering, University of KwaZulu-Natal, Howard College Campus, King George V Avenue, Durban 4041, South Africa

2 Department of Petroleum Engineering, Abadan Faculty of Petroleum Engineering, Petroleum University of Technology (PUT), Abadan, Iran

3 Department of Petroleum Engineering, Faculty of Engineering, Soran University, Kurdistan Region, Iraq
(Ahmed 2006; Mohammadi et al., 2012). The drop, in production pressure around the well in this type of reservoir, causes a two-phase flow due to the fluidization of a portion of the gas in this area (Arabloo et al. 2013; Kamari et al. 2016; Najafi-Marghmaleki et al. 2016, 2018). This twophase flow grows by moving the pressure profile toward the center of the produced well. With the loss of pressure below the dew point, the formed liquid may not be produced for some reasons and the relative permeability of the gas, especially around the well, can be reduced (Hinchman and Barree 1985; Lal 2003; Imo-Jack 2010). The pressure drop due to the blocking of condensate in this area can increase by about $200 \%$ of the pressure drop in the tubing (Rahimzadeh et al. 2016). Small absolute permeability and a tendency to condensation tend to cause trapping and adherence of the liquid phase onto the reservoir rock in this area. Besides, an interfacial tension (IFT) between two phases occurs due to the difference in density and the liquid phase and gas that exacerbate this effect and prevent the production of condensate (Rocke et al. 2008). This problem becomes more complex when there is water in addition to liquefied gas (Bang et al. 2008). This phenomenon, which is known as the liquid 
blockage occurs due to several factors, such as fluid phase properties, flow properties, reservoir pressure, and well pressure, and, if not prevented and treated, will disrupt the reservoir production function. For example, the Arun field in northern Sumatra, Indonesia, has experienced a considerable drop in pressure over a decade of production (Afidick et al. 1994). Also, Cupiagua Fields in Colombia, Karachaganak in Kazakhstan, and North Field in Qatar, 12, have suffered from this problem (Lee and Chaverra 1998; Al-Shammasi and D'Ambrosio 2003; Miller 2010). Different solutions have been proposed to sort out this problem, including hydraulic fracturing, acidizing, injection of solvents, and the alteration in the wettability of the reservoir rock to a moderate and highly gasphilic by chemical treatment (Fan et al. 2005; Wang et al. 2000; Al-Anazi et al. 2003; Du et al. 2000). When the reservoir rock becomes gasphilic, gaseous condensate and water clinging to the trapped surface of the rock are separated and produced, thereby the created excess pressure reduces. Many solvents, polymers, and surfactants have been synthesized by researchers for this purpose, with a wide range of them being in one aspect, and the presence of fluorine in the structure of chemicals. This is due to the evaporation of water and oil and the tendency to gasphilicity of such compounds (Linert 1997; Tang and Firoozabadi 2000). The use of these materials in solving the liquid blockage problem in gas condensate reservoirs was first reported by Li and Firoozabadi (2000). They treated samples of both chalk and sandstone in a solution of two fluoropolymers, branded FC754 and FC722. Their results show the average gas-bearing gasses by these two fluoropolymers. In the same year and also in 2003, Tang and Firoozabadi $(2000,2003)$ published similar studies with FC-722 and FC-759. Liu et al. (2006) used a new and inexpensive chemical called WA12. WA12 is stable at $170^{\circ} \mathrm{C}$ and salinity of $70000 \mathrm{ppm}$. The contact angle and imbibition tests reported by them show that the gasphilicity of the rock is possible by the claimed chemical, and flood testing shows that the relative permeability of both water and gas after chemical treatment increases. Kumar et al. (2006) investigated the possibility of chemical treatment around a gas condensate well with a new polymeric surfactant called FC4430. The results of their study show that treatment with this chemical could potentiate the production of gas condensate blocked around the well by gasification of this area and increasing relative permeability. Subsequently, Fahes and Firoozabadi (2007) examined the change in the gas density around the gas condensate wells by testing 10 chemical substances of the same group of materials. They used spontaneous imbibition and contact angle tests to show that the moderate gasphilicity and permeability using these groups of chemicals are possible. Their experiments were carried out at high temperatures. Al-Anazi et al. (2007) used two chemical groups, i.e. fluorosurfactants and silanes, to alter the wettability toward gasphilic. Using the contact angle experiments, they reported a moderate gasphilicity wettability in carbonate rocks and sandstone samples and considered factors such as the volume of chemical material, permeability, and temperature. Noh and Firoozabadi (2008), in gasphilic initiation studies of sandstone samples, looked at two different gas reservoirs by a fluorochemical surfactant namely 11-12P and a fluoroacrylate copolymer namely L-19062. Angular contact test and spontaneous imbibition test confirm the predominantly gaseous condition after treatment with these materials. Rocke et al. (2008), by performing flooding test using sandstone plasters treated with a nonionic fluorinated surfactant namely FC4430, showed that the relative permeability of the oil and gas phases increase as a result of the alteration of wettability to the gasphilicity. Their chemical substances were stable at high temperatures up to $175^{\circ} \mathrm{C}$. Bang et al. (2008) used $2 \mathrm{~W} \%$ of a fluorinated surfactant namely L19945 to treat a hydrophilic sandstone gas reservoir. They showed that the relative permeability of the gas due to the alteration of the wettability to the gasphilicity increases due to the treatment by this chemical substance. Denney (2009) examined the effect of salinity on the ability of fluorinated polymeric surfactants to chemically treat the rock toward gasphilicity. He concluded that $\mathrm{NaCl}$ salinity increases water wettability. $\mathrm{NaCl}$ also reduces the absolute permeability of the gas. The salinity of $\mathrm{CaCl}_{2}$ has a slight effect on permeability, and finally, $\mathrm{NaCl}, \mathrm{KCl}$, and $\mathrm{CaCl}_{2}$ salts have reverse effects on wettability alteration. Bang et al. (2009) performed a successful chemical treatment of a reservoir rock around the well damaged by water and condensate blocking using a nonionic polymeric fluorochemical mixture in glycol/alcohol and glycol ether/alcohol solvents. They reported a high potential of these chemicals in producing blocked fluids around the well. Wu and Firoozabadi (2010a) used fluorinated polymeric chemicals for the treatment of low-permeability sandstone. In addition to the formation of gasoline, the chemical reactions led to a change in the color between the silica surface and the used chemicals. In another study in 2010, the researchers looked at the effect of salinity on the gaseous process by a fluorinated polymeric surfactant commercially named Z8. In addition to observing the moderate gasphilicity, after treatment with $\mathrm{Z8}$, the rock was treated with a critical concentration for the stability of the used chemical material, along with the $\mathrm{NaCl}$ salinity ( $\mathrm{Wu}$ and Firoozabadi 2010b). Li et al. (2011), reported an increase in the production of gas condensate by wettability alteration toward gasphilicity by chemical treatment with WA12. Ahmadi et al. (2011) screened a wide range of fluorinated chemicals, selected the best material, demonstrated the use of flooding tests and the contact angle, and showed the gasphilic wettability and its effect on condensate production. Mousavi et al. (2013) synthesized the fluorocarbon nanostructures using a modified $\mathrm{SiO}_{2}$ nanoparticle and used it for 
this purpose. They obtained the final contact angle resulting from the treatment of the rock reservoir with these nanoparticles for water to be 147 and for n-decane to be 61 degrees. $\mathrm{Li}$ et al. (2014), using similar fluorescence superconductors, namely FC-1, and Zhang et al. (2014) from the polymerbased compound, namely Zony187040, used similar applications in the gas reservoir of Miyani. Wang et al. (2015) used two fluorosurfactants, namely FG24 and FG90. In addition to gasphilic creation, quartz samples were treated with surfactant solutions for optimal concentration to obtain more gasphilicity. Besides, in the same year, Fahimpour and Jamiolahmady (2015) optimized the ability of large range amounts of six fluorosurfactants in this process. Karandish et al. (2015) used an anionic fluorinated chemical substance. They observed an increase in the relative permeability of gas by chemical treatment of the rock. Another application of nanoparticles with the combination of silicon-based molecules and fluoro-polymer in the production of gasphilicity was presented by Aminnaji et al. (2015). Also, Jin et al. (2016) synthesized and used several silicon and fluorinebased nanocomposites. They showed the ability of these materials to produce gasphilicity using contact angle and imbibition tests; the gas phase was methane in their experiments. Saboori et al. $(2017,2018)$ used fluorine-coated silica nanoparticles, and Gahrooei and Ghazanfari (2017a, b) used a hydrocarbon-based chemical coated with fluorinated polymers, blue base nanoparticles, and fluorinated silicon-based molecules and developed the gasphilic production researches. Sakhaei et al. (2018) used fluorinated nanofluid to produce gasphilicity. Using the contact angle and imbibition tests, they were able to use fluoride nanosilicates in this process to eliminate the damage caused by blocking fluids in carbonate rocks. Hoseinpour et al. (2019), by treatment of the sandstone plugs in a novel fluorocarbon-based chemical solution, altered the wettability to gasphilic. Nowrouzi et al. (2020c) synthesized an anionic fluorinated surfactant and used it for chemical treatment and carbonate rock wettability alteration. Contact angle experiments showed the ability of the surfactant to chemical treat and wettability alteration of carbonate rocks to gas-wet. Gas-wettability of the rock has been studied in the field of $\mathrm{CO}_{2}$ storage in the reservoirs as well (Ali et al. 2019, 2020).

In this study, we investigated the effects of R134A and R404A gases on the alteration of wettability toward gasphilicity. This is a new application of these gases. Previously, they were used for applications such as refrigerant gases in refrigerators, as a propellant in aerosols, as a blowing agent for polymers, in perfumery, in astrophysics, and also as solvents in industrial detergents (Linde Group 2015). The adsorption of R134A and R404A on the surface and the property of being solvent in a liquid state due to their specific thermodynamics, along with the presence of these gases in the fluoride derivatives, were parts of the research hypothesis. In addition to environmental considerations, this application has also been taken into account. In other words, both of these gases are environmentally friendly, unlike the older ones used in their applications.

\section{Materials}

Carbonate rock samples were taken from Asmari Formation in Khuzestan, Iran. The used rock contains $61 \%$ dolomite and 39\% calcite. XRD and SEM analyses of the rock are presented in Fig. 1. The used gas condensate was extracted from South Pars reservoir with an API of 60.1 and acidity of $0.1 \mathrm{mg} \mathrm{KOH} / \mathrm{g}$. The components of the used gas condensate are reported in Table 1. Hydrocarbon gas with the information reported in Table 2 and air as gas phases were used. Toluene and acetone purchased from MP Biomedicals, Netherlands, with a purity of $99.9 \%$ were used to wash the device. R234A and R404A gases were used with the Honeywell brand. R134A gas is a pure gas, but R404A gas is a combined gas containing R143A (1,1,1-trifluoroethane), R125 (1,1,1,2,2-pentafluoroethane), and R134A (1,1,1,2-tetrafluoroethane). Table 3 reports the properties of R134A and R404A gases, and Fig. 2 shows the molecular structures of R134A, R125, and R143A gases.

\section{Equipment}

\section{Aging system}

For aging of the samples in the desired gases, the system was closed according to the schematic of Fig. 3. The system consists of a stainless steel cylinder as an aging enclosure. Another cylinder was fitted with a mobile piston for pressure, the end portion of which is a piston attached to a manual hydraulic pump. The upper outlet/inlet of the aging cylinder is connected to the vacuum pump on the one side and on the other side to the cylinder and piston and then to the gas cylinder. The aging system is inside an oven to apply the heat. After the evacuation, the valve is connected and the gas is introduced into the cylinder and the piston. When the valve is open, the gas is injected into the aging chamber where the rock sample is previously placed in the applied pressure by the manual hydraulic pump. To achieve higher pressure, this operation is repeated with an applied minus vacuum. It should be noted that the temperature and then the final pressure are set.

\section{Contact angle measurement device}

IFT400 device was used to measure the contact angles. This device provides the ability to measure the contact

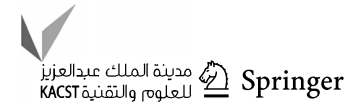


Fig. 1 XRD and SEM analyses of the used carbonate rock (Nowrouzi et al. 2020c)
Table 1 The gas condensate information (Nowrouzi et al. 2020c)
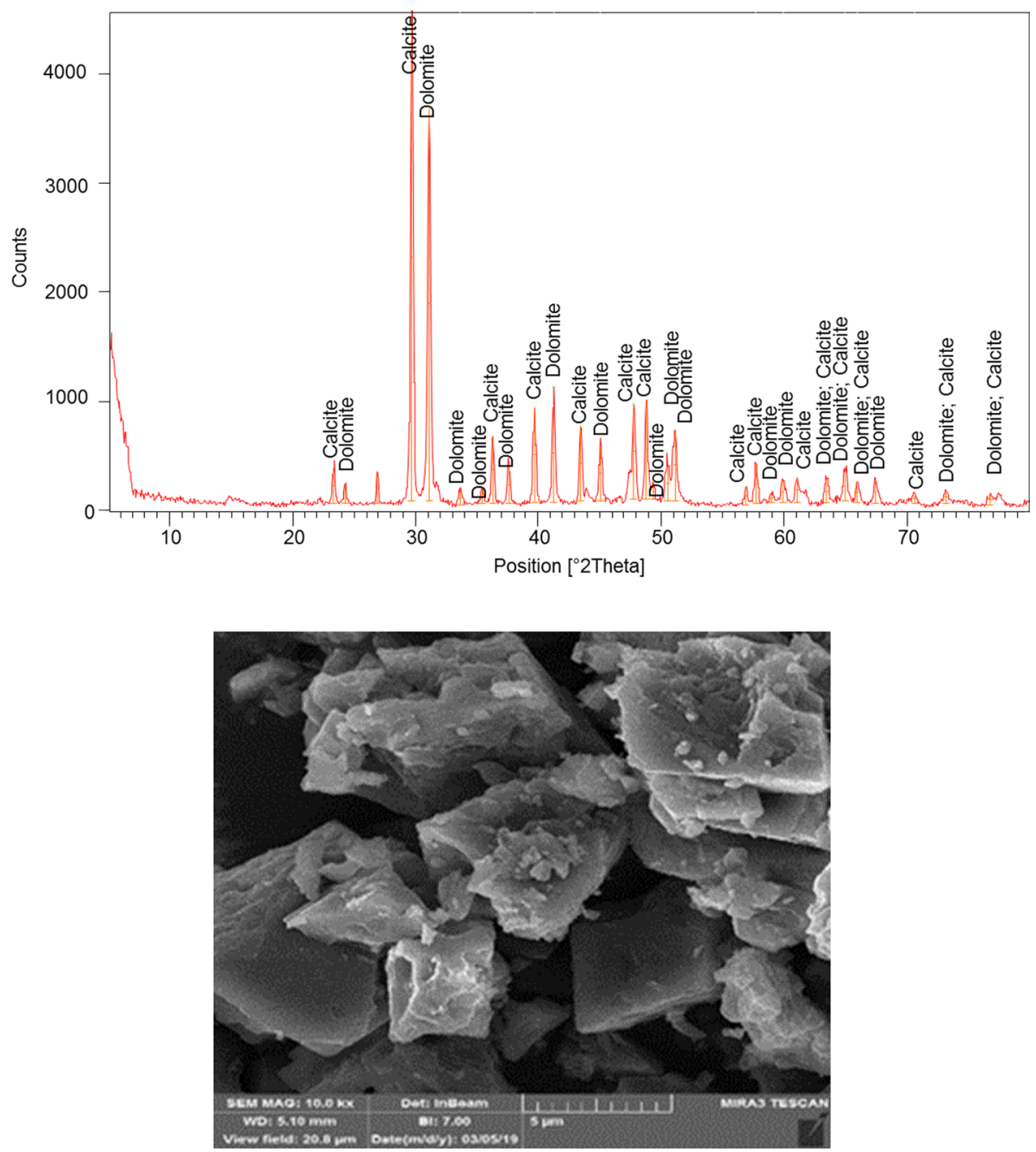

angle in the range of ambient temperature to $180^{\circ} \mathrm{C}$ and up to 3000 psi pressure. The device parts include two handheld spanners, which, in addition to mass storage and drip, also carry the device's pressure control function; the steel enclosure is equipped with two glass vents, one to the light source and the other to the camera connected to the computer. There is a heat jacket around the cell, in which three thermal elements are placed, using a PT-100 thermometer and a PID controller, to create a proper temperature control within $\pm 0.3{ }^{\circ} \mathrm{C}$. The pressure and temperature monitor displays the pressure and temperature of the device at any time, in addition to the two pressure gauges, one is used to control the pressure drop and the other to display the pressure on the device, which should report the same pressure during the test. The device is washed with toluene and acetone and then by passing high-pressure nitrogen through the lines and compartment of the device. The camera reports the instantaneous contents of the compartment to the software, and the software, after placing the baseline by the user, which distinguishes the surface of the rock and drop, draws two tangent lines in the two-dimensional image at the two sides of the droplet, and the angles of the left, right, and mean. The schematic of the device is shown in Fig. 4. 
Table 2 Hydrocarbon gas components

\begin{tabular}{lc}
\hline Component & Molar percent \\
\hline Methane & 87.7 \\
Ethane & 4.7 \\
Propane & 1.74 \\
Isobutane & 0.37 \\
n-Butane & 0.42 \\
Iso-pentane & 0.13 \\
n-Pentane & 0.10 \\
Hexane & 0.08 \\
Nitrogen & 4.7 \\
Carbon dioxide & 0.06 \\
Total & 100.00 \\
\hline
\end{tabular}

Table 3 Characterization of R134A and R404A gases

\begin{tabular}{lll}
\hline & R134A & R404A \\
\hline Molecular weight (MW) & 102.03 & 97.60 \\
Boiling point at $1 \mathrm{~atm}$ & $-26.06{ }^{\circ} \mathrm{C}$ & $-46.45^{\circ} \mathrm{C}$ \\
Critical temperature (Tc) & $101.08{ }^{\circ} \mathrm{C}$ & $72.07{ }^{\circ} \mathrm{C}$ \\
Critical pressure (Pc) & $4059 \mathrm{kPa}$ & $3729 \mathrm{kPa}$ \\
Critical density & $515.3 \mathrm{~kg} / \mathrm{m}^{3}$ & $484.5 \mathrm{~kg} / \mathrm{m}^{3}$ \\
\hline
\end{tabular}

Fig. 2 The molecular structures of R134A, R125, and R143A gases

\section{Liquid-gas imbibition system}

The schematic of the liquid-gas imbibition device is shown in Fig. 5. The basis of this system is to float a gas-saturated plug in a liquid container. The plug is connected to the hook of a force gauge with rope, which is held by an adjustable stand, and the force gauge indicates the weight of the floating plug with an uncertainty of $0.001 \mathrm{kgf}$, instantaneously. It is necessary to achieve a completely stagnant state and balance of floating plug during the experiment.

\section{Experimental procedure}

\section{Contact angle tests}

The narrow carbonate sections were cut from the rock sample. The sections were polished using unglazed porcelain. Nitrogen gas was used to remove particles and powder from the cutting. Subsequently, the sections were placed in toluene for 1 day to remove the fatty acids resulting from contact with the hands. However, the possibility of the fatty acid adsorption on the rock during cutting is very low and this stage of cleaning is done just to be surer. Toluene is an

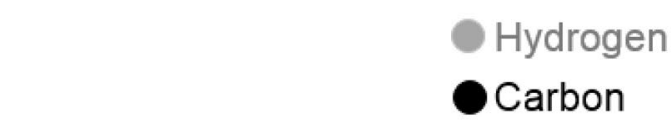

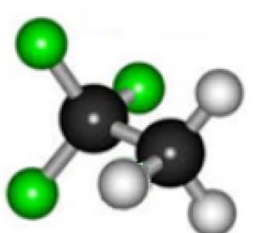

R143A

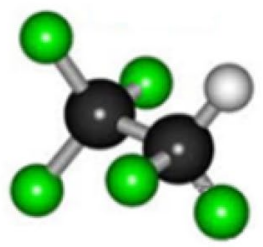

R125

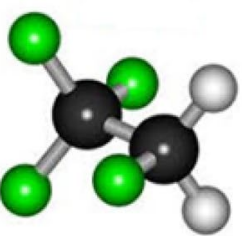

R134A

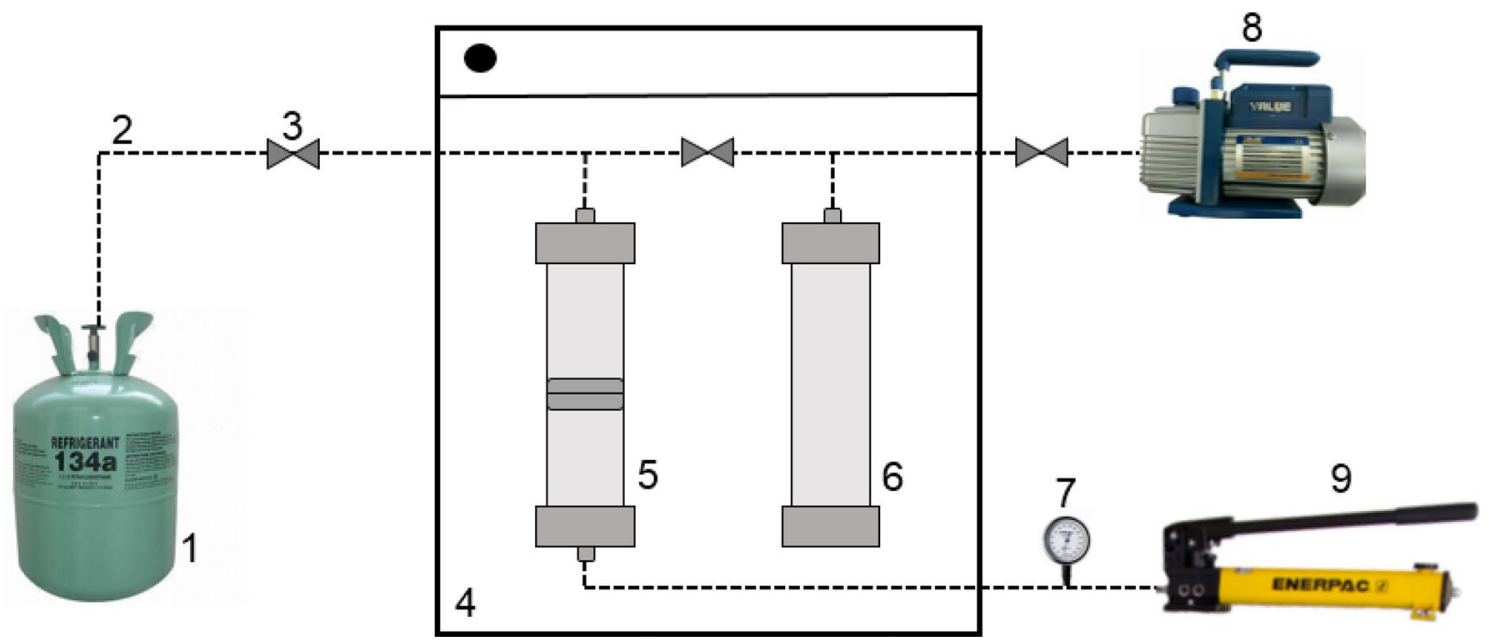

Fig. 3 Schematic of the rock aging system in R134A and R404A gases. 1: Gas tank, 2: steel line, 3: high-pressure valve, 4: oven, 5: cylinder and movable piston, 6: aging chamber, 7: pressure gauge, 8: vacuum pump, 9: manual hydraulic pump 


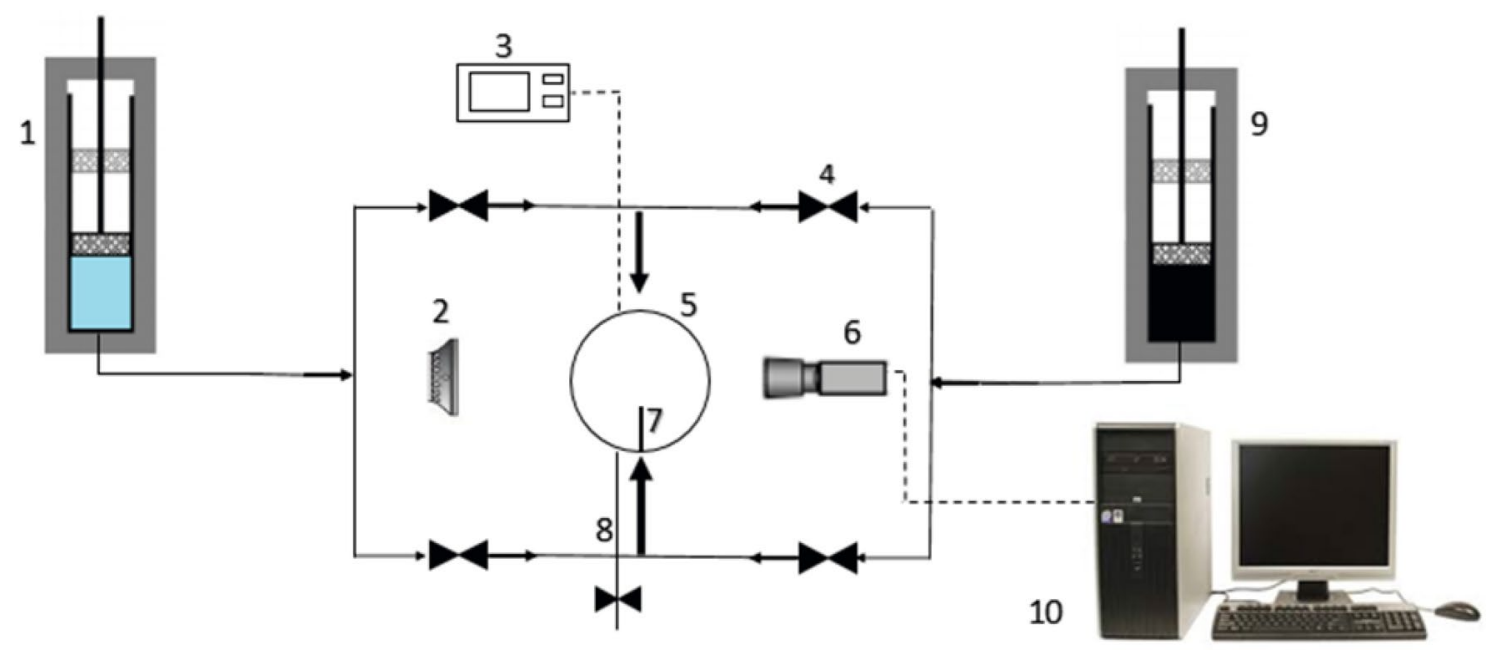

Fig. 4 Schematic of the IFT400. 1: Bulk flow pump. 2: Light source. 3: Indicator and regulator of temperature and pressure. 4: High-pressure valve. 5: Cell 6: Camera. 7: Metal needle. 8: Discharge line. 9:

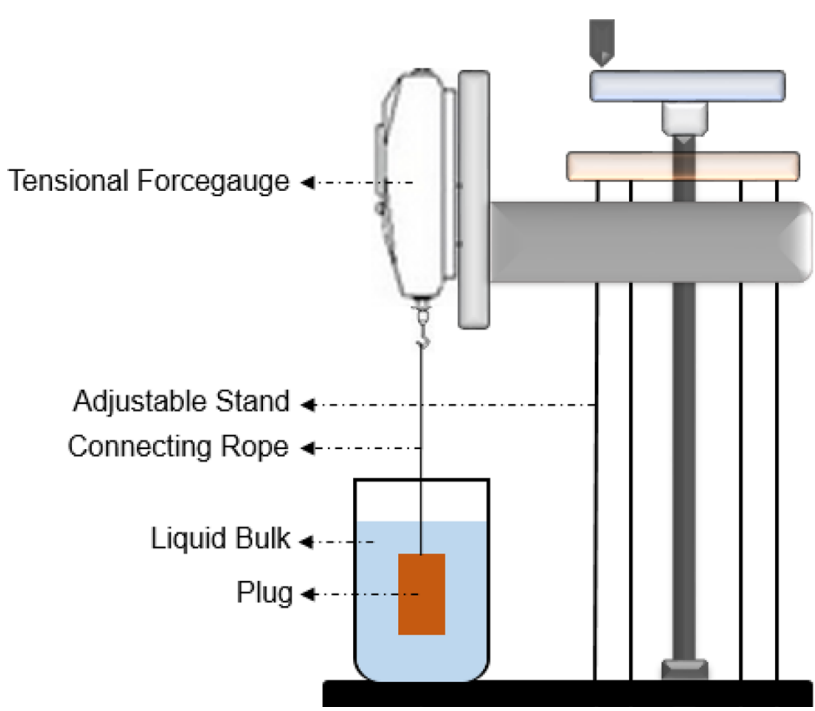

Fig. 5 Schematic of the liquid-gas imbibition system (Nowrouzi et al. 2020c)

aromatic hydrocarbon solvent, and finally, it may cause the rock to become hydrophobic. However, the aging time of a day is not enough for it. Thus, the washed and dried sections were placed in a sample of gas condensate for 12 days at $75^{\circ} \mathrm{C}$ for initial hydrophobicity formation (Manshad et al. 2017a, Nowrouzi et al. 2020a). Considering the volatility of gas condensate, the aging of the sections was performed to make the initial hydrophobicity in a sealed container. The contact angle tests were performed by IFT400 after the carbonate sections were exposed to R134A and R404A at pressures of 500,1000,1500, and $2000 \mathrm{psi}$ at a constant temperature of $70{ }^{\circ} \mathrm{C}$ and in the aging times of $12,24,36$,
Fluid drop pump. 10: Computer equipped with device software (Manshad et al., 2017b)

48, 60, and $72 \mathrm{~h}$ in the described system (Fig. 3). The aging times were considered for each level, meaning that a cross section was used for each period. It is worthwhile to mention that both the drop of water and condensate on each sample were measured so that two sides of each section were used for a drop of condensate and the other for a drop of water to identify the alteration of the wettability of each section relative to water and condensate and desire to be gasphilicity. The liquid drops contact angles were measured in the presence of the hydrocarbon gas and air as gas phases, as mentioned earlier.

\section{Imbibition tests}

The imbibition experiments followed a common routine trend in that the saturation plug of the gas is connected to a dynamometer or scale and float in the liquid. Then, the changes in the weight of the plug, which is caused by the liquids imbibition, are recorded. In this study, atmospheric pressure tests at $70^{\circ} \mathrm{C}$ were performed on the agglomerated plugs in R134A and R404A under the optimal condition from the previous step and on saturated air plugs and both of water and condensate by described liquid-gas imbibition system. Based on the changes in the weight of the plugs and the densities of the fluids, the volumes of imbibed fluids in the periods were measured and recorded. 


\section{Results and discussion}

\section{Contact angle tests' results}

The contact angle method is widely used to estimate surface wettability. When the alteration in wettability occurs, the contact angle before and after the alteration is the opposite. Effective parameters in wettability alteration include the properties of surface and additives in the injected fluid. For example, some clay minerals in the rock composition swell due to contact with water and create a microscopic roughness on the surface. This roughness can affect the contact angle (Marhaendrajana et al. 2018). The sessile drop contact angle is calculated by Young equation (Young 1805):

$\cos \theta=\frac{\gamma_{\mathrm{sv}}-\gamma_{\mathrm{sl}}}{\gamma}$

where $\theta$ represents the contact angle, $\gamma_{\mathrm{sv}}$ and $\gamma_{\mathrm{sl}}$ are the solid-gas and solid-liquid interfacial tensions, respectively, and $\gamma$ stands for the surface tension of the liquid.
Young equation considers the surface ideal, i.e., one that is atomically smooth, chemically homogeneous, nonreactive, and non-deformable by the liquid (Huhtamäki et al. 2018). In addition to these conditions, the volume of the drop and the gravity-induced sagging also affect the contact angle, and increasing the volume of the drop during the test increases the contact angle and the displacement of the lines (Huhtamäki et al. 2018; Srinivasan et al. 2011). To moderate this effect, contact angle experiments were performed for a fixed volume drop from the beginning of the experiment to the equilibrium moment. Other reactions leading to wetting and contact angle include adsorption and diffusion (Kaplan et al. 2013; Hoteit 2013; Santoso et al. 2016). Wettability alteration occurs by chemical and physical reactions between the active agents in the injected fluid and the rock surface (Chen et al. 2017). These reactions, regardless of their type, are not complete in an instant and require time. Chemical and physical reactions normally reach an equilibrium state over time. At equilibrium, the contact angle values tend to have a constant value. Therefore, it is necessary to spend enough time in contact angle tests. The results obtained from the contact angle in this study are
Table 4 The obtained information from contact angle tests from placing the water and condensate drops in the presence of the air on aged carbonate sections in $\mathrm{R} 134 \mathrm{~A}$ gas at $70{ }^{\circ} \mathrm{C}$ and different pressures of aging duration

Table 5 The obtained information from contact angle tests from placing the water and condensate drops in the presence of the air on aged carbonate sections in R404A gas at $70{ }^{\circ} \mathrm{C}$ and different pressures of aging duration

\begin{tabular}{|c|c|c|c|c|c|c|c|}
\hline \multirow[t]{3}{*}{ Liquid drop type } & \multirow{3}{*}{$\begin{array}{l}\text { Aging pres- } \\
\text { sure (psi) }\end{array}$} & \multicolumn{6}{|c|}{ Contact angle (degree) } \\
\hline & & \multicolumn{6}{|c|}{ Aging time (h) } \\
\hline & & 12 & 24 & 36 & 48 & 60 & 72 \\
\hline \multirow[t]{4}{*}{ Water } & 500 & 76.23 & 91.14 & 97.56 & 105.74 & 111.91 & 142.38 \\
\hline & 1000 & 81.13 & 94.96 & 103.41 & 109.57 & 117.63 & 143.20 \\
\hline & 1500 & 85.68 & 97.12 & 106.65 & 114.32 & 120.24 & 143.35 \\
\hline & 2000 & 89.72 & 104.91 & 109.25 & 118.03 & 126.81 & 144.89 \\
\hline \multirow[t]{4}{*}{ Condensate } & 500 & 87.41 & 92.13 & 101.02 & 107.57 & 115.29 & 136.33 \\
\hline & 1000 & 90.17 & 95.66 & 104.59 & 110.26 & 119.82 & 140.90 \\
\hline & 1500 & 91.04 & 97.65 & 109.13 & 114.91 & 126.40 & 153.09 \\
\hline & 2000 & 94.96 & 103.50 & 116.89 & 120.55 & 129.50 & 155.01 \\
\hline
\end{tabular}

\begin{tabular}{|c|c|c|c|c|c|c|c|}
\hline \multirow[t]{3}{*}{ Liquid drop type } & \multirow{3}{*}{$\begin{array}{l}\text { Aging pres- } \\
\text { sure (psi) }\end{array}$} & \multicolumn{6}{|c|}{ Contact angle (degree) } \\
\hline & & \multicolumn{6}{|c|}{ Aging time (h) } \\
\hline & & 12 & 24 & 36 & 48 & 60 & 72 \\
\hline \multirow[t]{4}{*}{ Water } & 500 & 104.88 & 110.56 & 117.83 & 122.80 & 128.62 & 145.85 \\
\hline & 1000 & 109.12 & 114.70 & 123.95 & 129.19 & 134.31 & 150.29 \\
\hline & 1500 & 115.08 & 121.49 & 130.68 & 138.44 & 146.51 & 153.38 \\
\hline & 2000 & 125.91 & 134.47 & 140.10 & 144.09 & 151.64 & 155.56 \\
\hline \multirow[t]{4}{*}{ Condensate } & 500 & 85.15 & 91.75 & 94.18 & 101.32 & 109.62 & 144.88 \\
\hline & 1000 & 86.18 & 93.63 & 99.71 & 105.66 & 111.03 & 145.01 \\
\hline & 1500 & 91.21 & 96.10 & 104.16 & 109.89 & 114.78 & 146.61 \\
\hline & 2000 & 95.14 & 102.76 & 111.95 & 116.72 & 123.06 & 152.44 \\
\hline
\end{tabular}


all equilibrium values. Table 4 reports the results of the angle tests obtained from the placing of water and condensate droplets in the presence of the air on the aged sections in R134A, and Table 5 indicates the results of the measured contact angles of water and condensate droplets in the presence of the air on the aged sections in R404A.
Table 6 The obtained information from contact angle tests from placing the water and condensate drops in the presence of the hydrocarbon gas on aged carbonate sections in $\mathrm{R} 134 \mathrm{~A}$ gas at $70{ }^{\circ} \mathrm{C}$ and different pressures of aging duration

\begin{tabular}{|c|c|c|c|c|c|c|c|}
\hline \multirow[t]{3}{*}{ Liquid drop type } & \multirow{3}{*}{$\begin{array}{l}\text { Aging pres- } \\
\text { sure (psi) }\end{array}$} & \multicolumn{6}{|c|}{ Contact angle (degree) } \\
\hline & & \multicolumn{6}{|c|}{ Aging time (h) } \\
\hline & & 12 & 24 & 36 & 48 & 60 & 72 \\
\hline \multirow[t]{4}{*}{ Water } & 500 & 78.37 & 81.20 & 82.54 & 83.11 & 86.98 & 92.31 \\
\hline & 1000 & 89.40 & 90.24 & 93.98 & 94.08 & 96.14 & 97.01 \\
\hline & 1500 & 91.18 & 95.70 & 97.93 & 101.17 & 104.22 & 109.84 \\
\hline & 2000 & 101.15 & 106.59 & 109.56 & 111.67 & 115.63 & 120.97 \\
\hline \multirow[t]{4}{*}{ Condensate } & 500 & 77.93 & 79.69 & 81.67 & 85.81 & 89.49 & 90.14 \\
\hline & 1000 & 91.24 & 94.02 & 94.80 & 96.22 & 99.52 & 102.49 \\
\hline & 1500 & 118.12 & 120.36 & 125.06 & 127.41 & 130.78 & 135.35 \\
\hline & 2000 & 119.05 & 123.49 & 126.19 & 130.07 & 132.64 & 136.91 \\
\hline
\end{tabular}

\begin{tabular}{|c|c|c|c|c|c|c|c|}
\hline \multirow[t]{3}{*}{ Liquid drop type } & \multirow{3}{*}{$\begin{array}{l}\text { Aging pres- } \\
\text { sure (psi) }\end{array}$} & \multicolumn{6}{|c|}{ Contact angle (degree) } \\
\hline & & \multicolumn{6}{|c|}{ Aging time (h) } \\
\hline & & 12 & 24 & 36 & 48 & 60 & 72 \\
\hline \multirow[t]{4}{*}{ Water } & 500 & 110.73 & 113.16 & 115.01 & 119.22 & 121.14 & 127.72 \\
\hline & 1000 & 109.92 & 114.45 & 117.31 & 120.87 & 122.02 & 127.73 \\
\hline & 1500 & 120.25 & 122.50 & 126.24 & 129.66 & 130.16 & 132.25 \\
\hline & 2000 & 121.12 & 125.75 & 128.83 & 130.73 & 134.75 & 136.33 \\
\hline \multirow[t]{4}{*}{ Condensate } & 500 & 117.06 & 120.91 & 122.15 & 125.19 & 126.14 & 127.73 \\
\hline & 1000 & 119.34 & 121.83 & 125.09 & 128.21 & 131.91 & 135.69 \\
\hline & 1500 & 126.41 & 127.59 & 130.10 & 132.56 & 136.23 & 138.58 \\
\hline & 2000 & 130.55 & 131.66 & 132.29 & 137.70 & 138.65 & 139.44 \\
\hline
\end{tabular}

Fig. 6 The obtained curves from the contact angle experiments due to the droplet of water and condensate in the presence of the air on the aged carbonate sections of R134A gas at $70^{\circ} \mathrm{C}$ and different pressures of aging duration
Table 7 The obtained information from contact angle tests from placing the water and condensate drops in the presence of the hydrocarbon gas on aged carbonate sections in $\mathrm{R} 404 \mathrm{~A}$ gas at $70^{\circ} \mathrm{C}$ and different pressures of aging duration

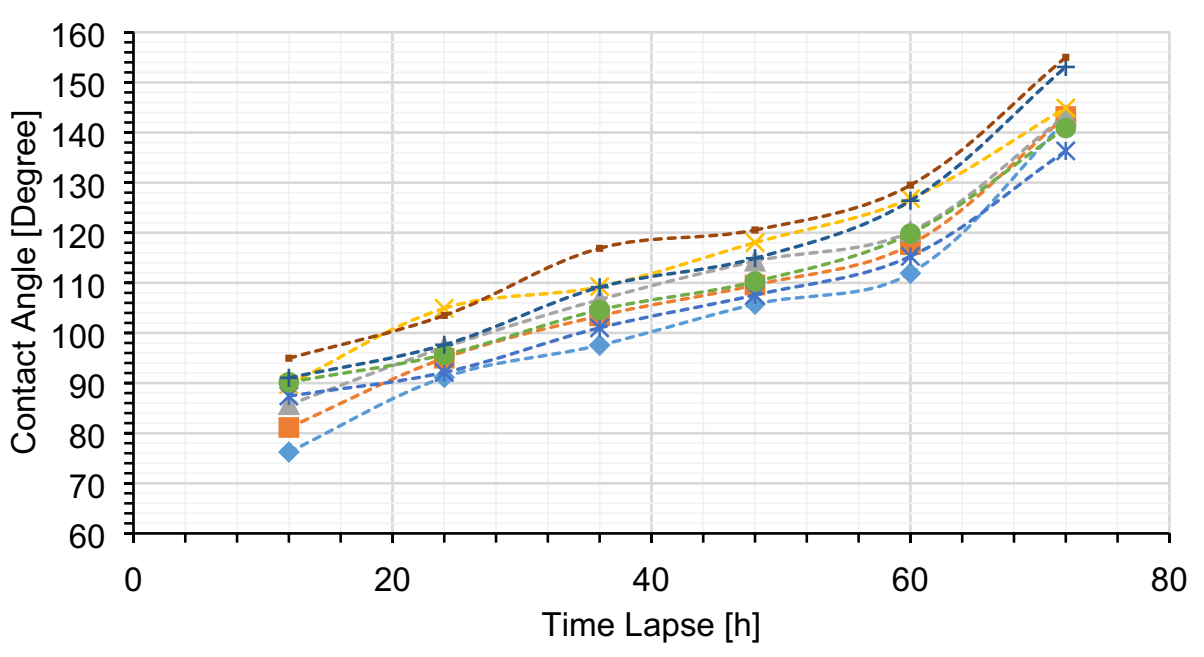


Fig. 7 The obtained curves from the contact angle experiments due to the droplet of water and condensate in the presence of the air on the aged carbonate sections of R404A gas at $70{ }^{\circ} \mathrm{C}$ and different pressures of aging duration
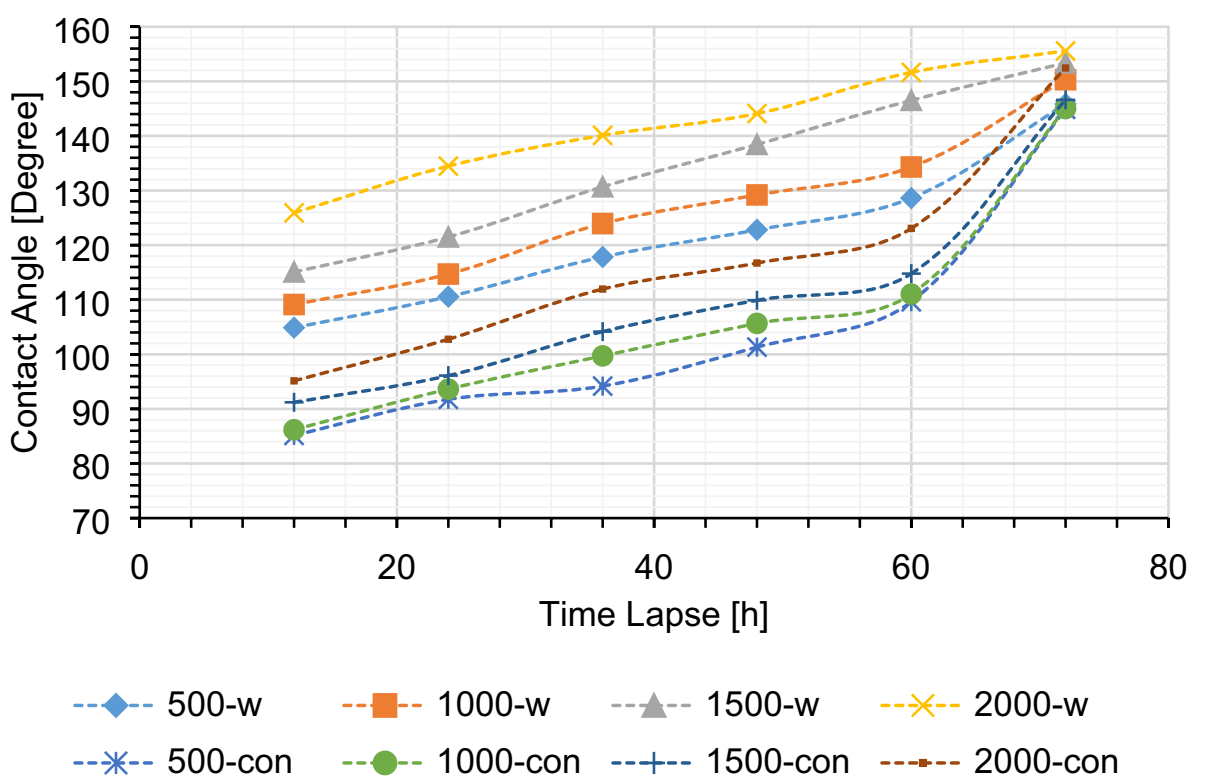

Fig. 8 The obtained curves from the contact angle experiments due to the droplet of water and condensate in the presence of the hydrocarbon gas on the aged carbonate sections of R134A gas at $70{ }^{\circ} \mathrm{C}$ and different pressures of aging duration

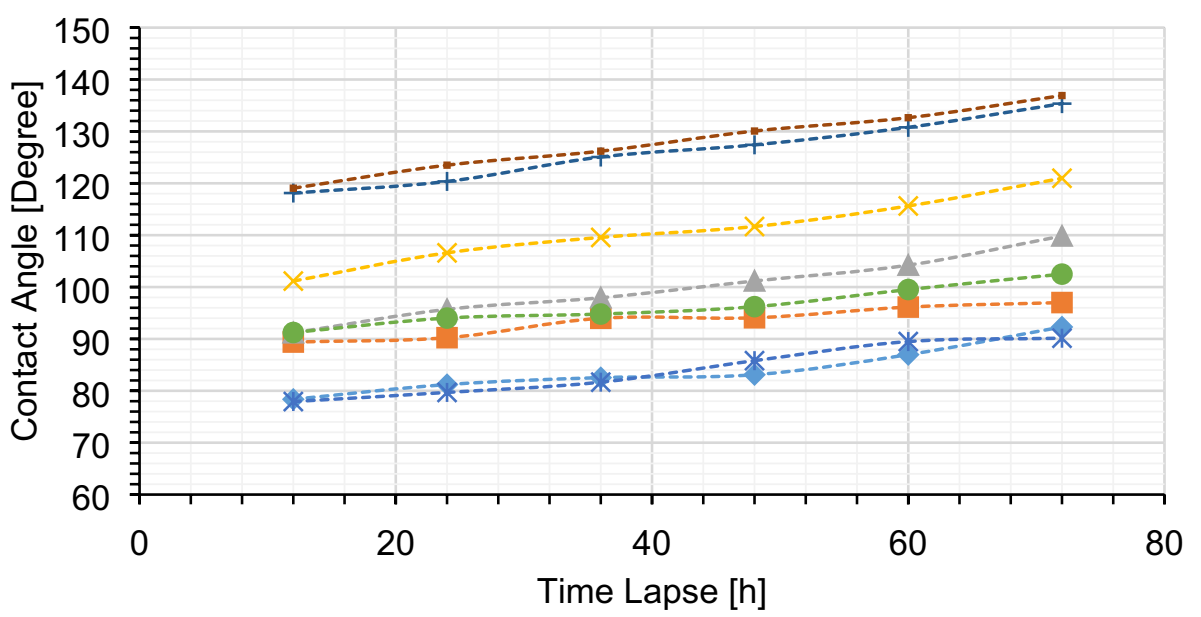

$----500-w$
$--*--500-c o n$

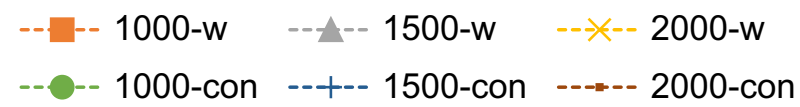

Table 6 shows the results of the angle tests obtained from the placing of water and condensate drops in the presence of the hydrocarbon gas on the aged sections in R134A, and Table 7 indicates the results of the measured contact angles of water and condensate droplets in the presence of the hydrocarbon gas on the aged sections in R404A gas at pressures of $500,1000,1500$, and 2000 psi at a constant temperature of $70{ }^{\circ} \mathrm{C}$ and at an aging time of $12,24,36$, 48,60 , and $72 \mathrm{~h}$. Figure 6 shows the information reported in Table 4, Fig. 7 presents the diagram for the information reported in Table 5, Fig. 8 presents the diagram for the information reported in Table 6, and Fig. 9 shows the graphs based on Table 7. Finally, Fig. 10 shows the images of the water and condensate droplets on aged sections in $\mathrm{R} 134 \mathrm{~A}$ and $\mathrm{R} 404 \mathrm{~A}$ at $70{ }^{\circ} \mathrm{C}, 2000 \mathrm{psi}$, and $72 \mathrm{~h}$ of aging time. Information in the tables shows that the aging time of samples in the gases is very important, and after that, the pressure plays the main role. Consequently, according to Table 4 at a constant temperature of $70{ }^{\circ} \mathrm{C}$, taking into account the pressure rise of $2000 \mathrm{psi}$, the angles of contact are obtained due to the drop of water on the sample of agglomerated carbonate in the presence of the air and the periods of $12,24,36,48,60$, and $72 \mathrm{~h}$ are $89.72,104.91$, $109.25,118.03,126.81$, and 144.89 degrees, respectively. 
Fig. 9 The obtained curves from the contact angle experiments due to the droplet of water and condensate in the presence of the hydrocarbon gas on the aged carbonate sections of R404A gas at $70{ }^{\circ} \mathrm{C}$ and different pressures of aging duration
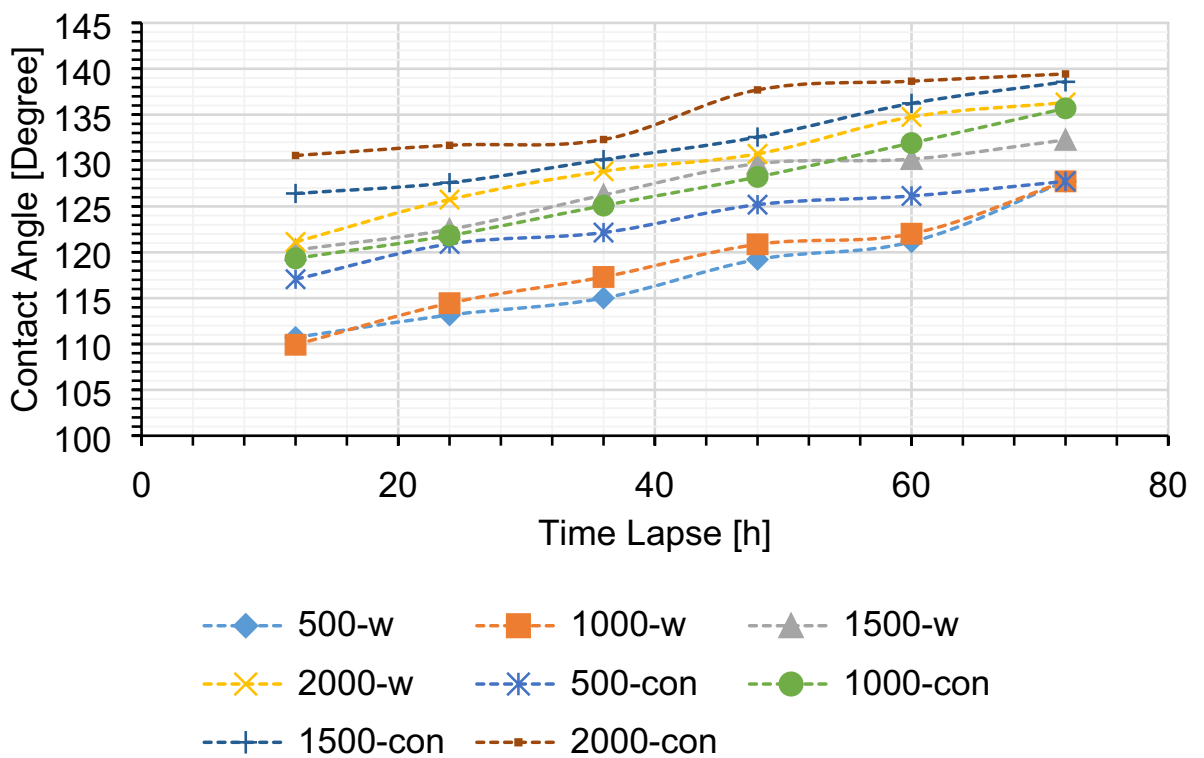

Also, the contact angles of the water droplets with a constant time of $72 \mathrm{~h}$ at pressures of 500, 1000, 1500 and 2000 psi are $142.38,143.20,143.35$, and 134.89 degrees, respectively (1st row of Fig. 10). This process was also achieved with slightly different values for the contact angle between condensate droplets and carbonate rocks. For example, at a constant temperature of $70{ }^{\circ} \mathrm{C}$ and pressure of $2000 \mathrm{psi}$, the contact angles for condensate droplets in the presence of the air during the aging periods of 12, 24, $36,48,60$, and $72 \mathrm{~h}$ were $94.96,103.50,116.89,120.55$, 129.50 , and 155.01 degrees, respectively. With a constant time of $72 \mathrm{~h}$ at the test temperature, the condensate droplet angles at the pressures of 500, 1000, 1500 and 2000 psi were $136.33,140.90,153.09$, and 155.01 degrees, respectively (1st row of Fig. 10). Referring to Table 5 for the contact angles of the drops of water and condensates on the sample surface of the aged rock in the presence of the air at various supercritical pressures of R404A at $70{ }^{\circ} \mathrm{C}$ and $12,24,36,48,60$, and $72 \mathrm{~h}$ shows a similar trend versus pressure and aging time. The highest gas content was obtained by R404A concerning the greater contact angle at an aging pressure of $2000 \mathrm{psi}$ and an aging time of $72 \mathrm{~h}$. The contact angles of the drop of water and condensate at this condition are 155.56 and 152.44 degrees, respectively. Concerning pressure at $2000 \mathrm{psi}$ and 12, 24, 36, 48, 60, and $72 \mathrm{~h}$ for the aging of sections in R404A gas, the angles of contact of the drop of water in the presence of the air were $125.91,134.47,140.10,144.09,151.64$, and 155.56 degrees and the condensate drop contact angle values were $95.14,102.76,111.95,116.72,123.06$, and 152.44 degrees, respectively. The contact angles of the water droplets in the presence of the air with a constant time of $72 \mathrm{~h}$ at pressures of 500, 1000, 1500, and 2000 psi are 145.85 ,
$150.29,153.38$, and 155.56 degrees and the condensate droplet angles at the pressures of 500, 1000, 1500, and 2000 psi were $144.88,145.01,146.61$, and 152.44 degrees, respectively (2nd row of Fig. 10). According to Table 6 at a constant temperature of $70{ }^{\circ} \mathrm{C}$, taking into account the pressure rise of $2000 \mathrm{psi}$, the angles of contact obtained due to the drop of water on the sample of aged carbonate in $\mathrm{R} 134 \mathrm{~A}$ in the presence of the hydrocarbon gas in the periods of $12,24,36,48,60$, and $72 \mathrm{~h}$ are $101.15,106.59$, $109.56,111.67,115.63$, and 120.97 degrees and the contact angles of the water droplets in the presence of the hydrocarbon gas with a constant time of $72 \mathrm{~h}$ at pressures of $500,1000,1500$, and 2000 psi are 92.31, 97.01, 109.84, and 120.97 degrees, respectively (3rd row of Fig. 10). At a constant temperature of $70{ }^{\circ} \mathrm{C}$ and pressure of $2000 \mathrm{psi}$, the contact angles for condensate droplets in the presence of the hydrocarbon gas during the aging periods of 12 , $24,36,48,60$, and $72 \mathrm{~h}$ were $119.05,123.49,126.19$, $130.07,132.64$, and 136.91 degrees, and with a constant time of $72 \mathrm{~h}$ at the test temperature, the condensate droplet angles at the pressures of 500, 1000, 1500, and $2000 \mathrm{psi}$ were $90.14,102.49,135.35$, and 136.91 degrees, respectively (3rd row of Fig. 10). According to Table 7, for the contact angles of the drops of water and condensates on the sample surface of the aged rock in the presence of the hydrocarbon gas at various supercritical pressures of $\mathrm{R} 404 \mathrm{~A}$, concerning pressure at $2000 \mathrm{psi}$ and $12,24,36$, 48,60 , and $72 \mathrm{~h}$, the contact angles of the drop of water in the presence of the hydrocarbon gas were 121.12, 125.75, $128.83,130.73,134.75$, and 136.33 degrees and the condensate drop contact angle values were 130.55, 131.66, $132.29,137.70,138.65$, and 139.44 degrees, respectively. The contact angles of the water droplets in the presence 


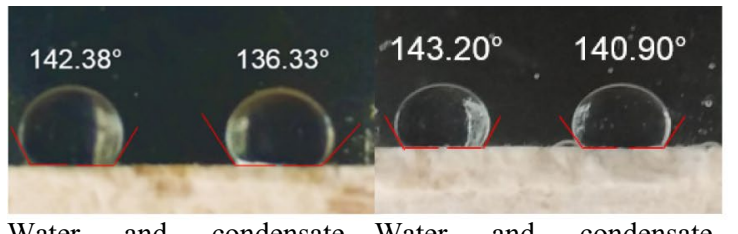

Water and condensate Water and condensate droplets in the presence of droplets in the presence of the air on an aged rock in the air on an aged rock in R134A@500psi.

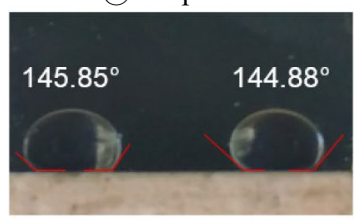

Water and condensate droplets in the presence of the air on an aged rock in R404A@ 500psi.

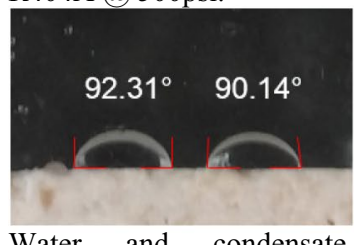

Water and condensate droplets in the presence of the hydrocarbon gas on an aged rock in R134A @ 500 psi.

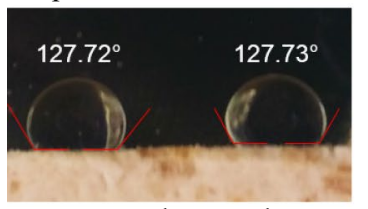

Water and condensate droplets in the presence of the hydrocarbon gas on an aged rock in R404A@ 500 psi.
R134A@1000psi.

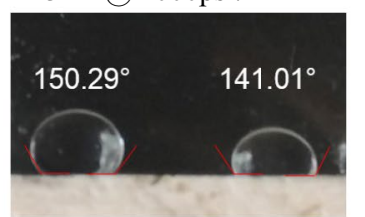

Water and condensate droplets in the presence of the air on an aged rock in R404A@1000psi.

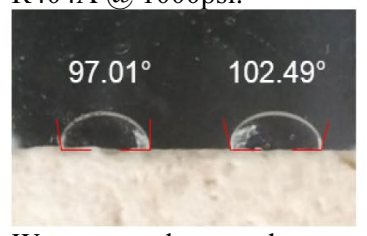

Water and condensate droplets in the presence of the hydrocarbon gas on an aged rock in R134A @ 1000 psi.

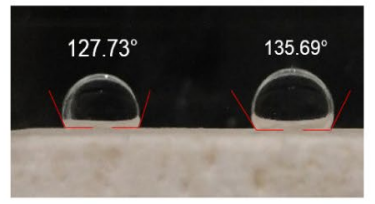

Water and condensate droplets in the presence of the hydrocarbon gas on an aged rock in R404A @ 1000 psi.

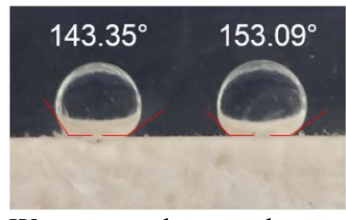

Water and condensate droplets in the presence of the air on an aged rock in R134A@1500psi.

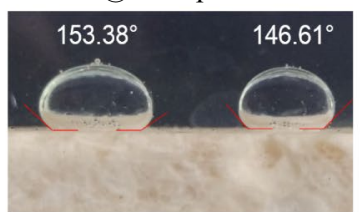

Water and condensate droplets in the presence of the air on an aged rock in R404A@1500psi.

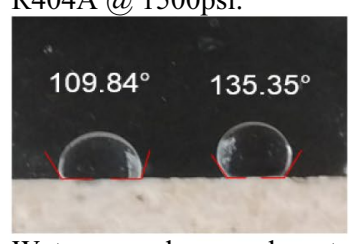

Water and condensate droplets in the presence of the hydrocarbon gas on an aged rock in R134A a 1500 psi.

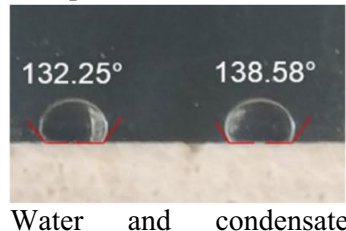
droplets in the presence of the hydrocarbon gas on an aged rock in R404A @ 1500 psi.

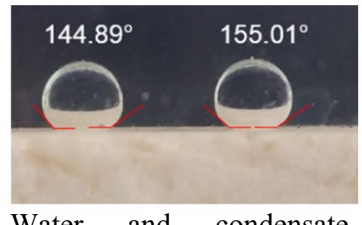

Water and condensate droplets in the presence of the air on an aged rock in R134A@1500psi.

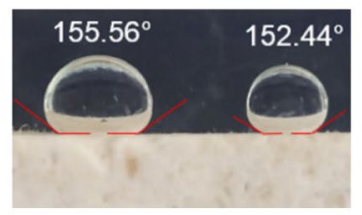

Water and condensate droplets in the presence of the air on an aged rock in R404A@2000psi.

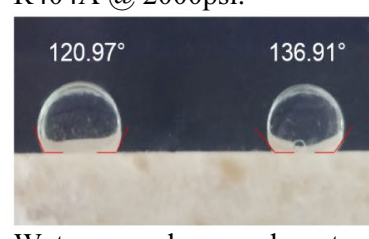

Water and condensate droplets in the presence of the hydrocarbon gas on an aged rock in R134A @ 2000 psi.

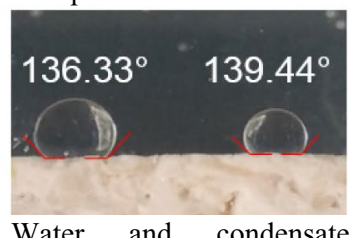

condensate droplets in the presence of the hydrocarbon gas on an aged rock in R404A@ 2000psi.
Fig. 10 Images of water and condensate droplets in the presence of the air and hydrocarbon gas on aged carbonate sections in R134A and R404A gases at a constant temperature of $70{ }^{\circ} \mathrm{C}$, different pressures,

of the hydrocarbon gas with a constant time of $72 \mathrm{~h}$ at pressures of 500,1000, 1500, and 2000 psi are 127.72 , $127.73,132.25$, and 136.33 degrees and the condensate droplet angles at the pressures of 500, 1000, 1500, and 2000 psi were $127.73,135.69,138.58$, and 139.44 degrees, respectively (4th row of Fig. 10).

The alteration in wettability to gasphilic is explained by the adsorption phenomenon of fluorinated gases of R134A and R404A and then the frequency of fluorine in their composition. The amount of adsorption of R134A and R404A, similar to the other gases, in addition to the chemical properties of absorbent and adsorbent to the temperature, also depends on the pressure (Kılıç and Gönül 2016; Rudzinski and Everett 2012). The magnitude of adsorption increases and a duration of $72 \mathrm{~h}$ (the left drops are water and the right are gas condensates)

with an increase in pressure. The relationship between the magnitude of adsorption and pressure can be expressed mathematically by Freundlich adsorption isotherm for gases (Rogers and Sclar 1932):

$\frac{x}{m}=K p^{n}$

where $x$ is the mass of the gas adsorbed on mass $m$ of the adsorbent at the equilibrium pressure $\mathrm{p}$ and $K$ and $n$ are constants depending upon the nature of gas and adsorbent. However, $\mathrm{x} / \mathrm{m}$ does not increase as rapidly as $p$. The amount of contact angle obtained here can represent the amount of adsorption of these gases on the carbonate rock, so the exposure time of the surface of the rock exposed to gas is also an 
effective factor in this phenomenon. Adsorption of gases on the surface may be of a physical, chemical, or both nature. However, the adsorption of R134A and R404A gases occurs physically due to their low reactivity. The physical adsorption phenomenon occurs mainly within the pores and on the surface of the adsorbent since the characteristics of each adsorbent-adsorbate pair are different than others (Kılıç and Gönül 2016). Contact angle values for the aged sections in R404A gas show larger values. This may be due to the presence of more fluorine atoms in R125 gas in the R404A gas. Besides, the physical characteristics of the surface are very important. Gas molecules first enter the narrow compartments on the surface, and after filling the shield, the gas enters larger compartments. Interactions between gases and the surface are stronger in the narrower holes and weaker in the surface and the larger holes (Kılıç and Gönül 2016). Eventually, a film of fluoride gas is created on the surface that can produce oleophobic properties at the surface. This property of fluorinated gases is used to create oleophobic layer on the surface of electronic tools such as screens and handsets for protecting moisture (Milella et al. 2004). In this way, the adsorption is caused by the intermolecular force that exists between adsorbates and adsorbents. The adsorption is known as van der Waals adsorption. Since van der Waals force exists between any two molecules, physical adsorption can occur on any solid surface. Since physisorption is caused by intermolecular forces, the binding force is weak with less adsorption, and the rate of adsorption and desorption is fast. The adsorbed substance is also easier to desorb, so the physical adsorption is reversible to a certain extent (Deng et al. 2019), but at a stable thermodynamic condition, the amount of adsorption reaches a critical value. These interpretations do not mean that surface wettability is only a function of the adsorption of gases on the surface. Other factors, such as the presence of reservoir fluid, may alter the surface properties by interacting with the rock. There is not only a solid-gas system but also a solid surface-liquid-gas system. Interactions that occur in the presence of liquid may be chemical or physical and affect the properties of the surface, including wettability (Bartali et al. 2017). The adsorption process on reservoir rock is normally influenced by the chemical and physical properties of the adsorbent and adsorbed substance. For example, just as in the adsorption of polymers, even the molecular weight of the polymer affects the fluid-rock interactions (Torrealba and Hoteit 2019), so the molecular weights of the gases also affect the intermolecular forces and ultimately the adsorption, but there may not be a definite trend for either. Another

Table 8 Information about the plugs used in the imbibition tests

\begin{tabular}{llllllll}
\hline Plug no. & Perm. $(\mathrm{md})$ & Por. $(\%)$ & $L(\mathrm{~cm})$ & $D(\mathrm{~cm})$ & $V_{\mathrm{P}}\left(\mathrm{cm}^{3}\right)$ & Imbibition fluid & Aging condition \\
\hline 1 & 22.05 & 13.94 & 7.00 & 3.81 & 11.12 & Water & - \\
2 & 24.83 & 16.07 & 7.00 & 3.81 & 12.82 & Water & $72 \mathrm{~h}$ aged in R134A @ 2000psi, 70 ${ }^{\circ} \mathrm{C} \mathrm{144.89}$ \\
3 & 21.91 & 14.33 & 7.00 & 3.81 & 11.43 & Water & $72 \mathrm{~h}$ aged in R404A @ 2000psi, 70 ${ }^{\circ} \mathrm{C} \mathrm{155.56}$ \\
4 & 25.46 & 15.61 & 7.00 & 3.81 & 12.45 & Condensate & - \\
5 & 22.79 & 14.88 & 7.00 & 3.81 & 11.87 & Condensate & $72 \mathrm{~h}$ aged in R134A @ 2000psi, 70 ${ }^{\circ} \mathrm{C} \mathrm{155.01}$ \\
6 & 20.18 & 14.72 & 7.00 & 3.81 & 11.74 & Condensate & $72 \mathrm{~h}$ aged in R404A @ 2000psi, 70 ${ }^{\circ} \mathrm{C} 152.44$ \\
\hline
\end{tabular}

Fig. 11 The curves of the imbibition experiment results at $70{ }^{\circ} \mathrm{C}$ and atmospheric pressure

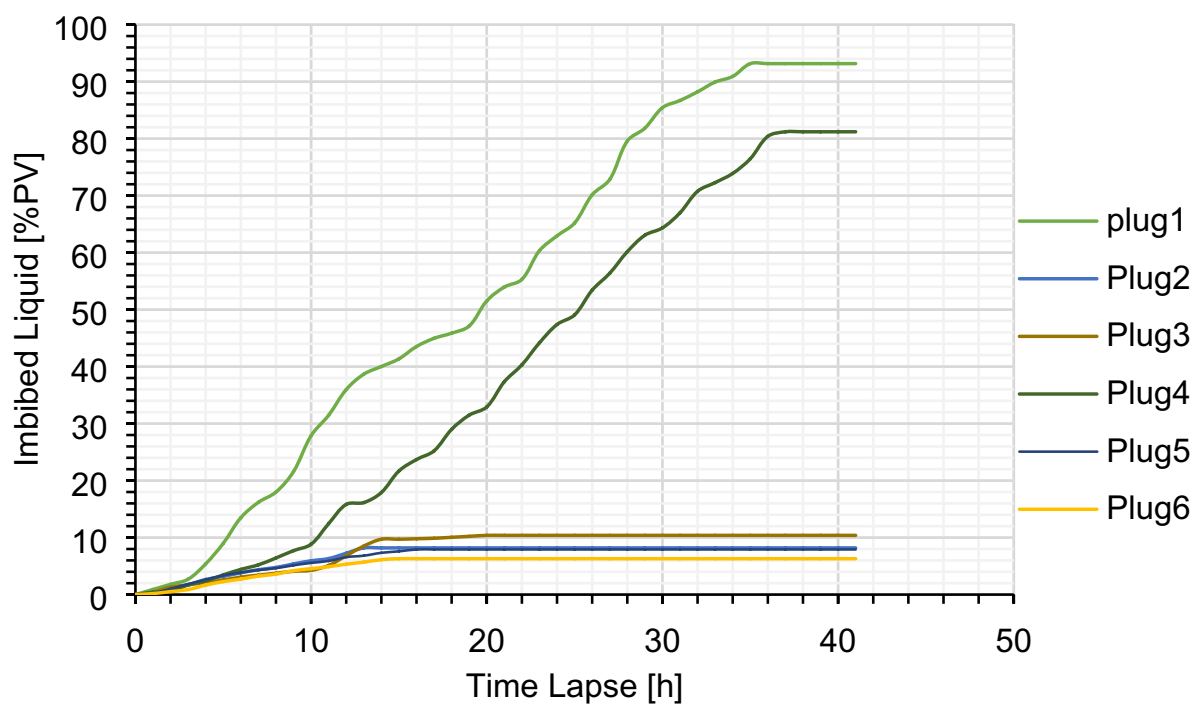


point in the experiments of the contact angle and the shape and angle of the liquid droplet on the surface of the aged rock is the surface tension of the liquid drop placed on the surface in the presence of air. The surface tension of the drop can affect the contact angle (Dandekar 2013).

\section{Imbibition tests' results}

Table 8 presents the information for the plugs, and Fig. 11 shows the information obtained from the imbibition by water and the condensate of gas saturated plugs before any aging and after aging in R134A and R404A gases. The time and condition of the plug aging were equivalent to the optimum conditions obtained from the angular contact tests on the gas side and the contact angle, i.e., $2000 \mathrm{psi}$ and $72 \mathrm{~h}$. In this order, with optimal conditions and comparing them with the ones in the unaged plugs, six experiments were carried out. The results of the imbibition experiments, according to Fig. 11, confirm the wettability alteration by the used fluorinated gases, the same as contact tests. Accordingly, the plugs with initial wettability imbibed water and condensate about 93 and 81 percent of PV after 35 and $37 \mathrm{~h}$, respectively. This is a sign of the strong initial liquid-wet of the plug. According to the drawn curves in Fig. 11, the aged plug with R134A and immersed in a water and condensate environment imbibed 8.1 and $7.9 \%$ of the initial PV, respectively. These values for aged plug in the R404A for water and condensate were 6.2 and $10.3 \%$, respectively. It should be noted that the imbibition time for the aged and unaged plugs is very different, which means that the imbibition in aged plugs of R134A immersed in water and condensates was stopped at 16 and $13 \mathrm{~h}$, respectively. This time for aged plugs in the R404A for condensate and water was 15 and $20 \mathrm{~h}$, respectively. The higher imbibition rate in the aged plug in the R134A gas shows good agreement of the contact angle and imbibition results. This adaptation is due to the imbibition dependence on the wettability of the rock (Nowrouzi et al. 2020b, d). Previous contact angle tests have shown that wettability alteration is better performed by the R404A gas, and more contact angle values are obtained. In the imbibition experiments, the aged plugs in the R404A gas with higher gas-wet plugs yielded lower imbibition rates. However, there may not be an exact linear relationship between the contact angle and the imbibition rate due to differences in the characteristics of the sections surface and the plug-porous medium surface. The same low-liquid imbibition in aged plugs can have several reasons: First, zero imbibition rate for a completely gasphilicity, so that the contact angle of the liquid and the surface of the rock is close to $180^{\circ}$, and that the low increase in the weight of the plug may result in bubbles that have a weak adhesion on the outer surface of the plugs. The bubbles could not overcome the buoyancy forces when the plug was immersed in the liquid, and they had to be separated from the level of the plug and come out of the liquid container. In tests of contact angle, the sections were polished, which could reduce the adsorption of the gases. But in the porous medium, there is no polished surface, and there are plenty of cavities and screws in the shaft that increase the adsorption of the gases. Therefore, imbibition experiments can provide good conditions from this point of view. The dependence of the imbibition on the wettability of the rock makes it possible to more imbibed water and condensate by the aged plugs in the desired fluorinated gases, which can be linked into a more wettability toward gas-wet. Although a set of parameters are effective on the wettability alteration of reservoir rock, in this study, the effects of pressure and aging time at a constant temperature were investigated. Reservoir rock wettability was tested by the methods of contact angle and imbibition under optimal conditions. Aging time and pressure as input parameters and the contact angle as output parameter were considered in the sensitivity analysis of them. The impact of input parameters on output parameter and parameter screening is required before sensitivity analysis (Santoso et al. 2020). Based on the results and comparing the values, the aging time has the greatest effect on the amount of contact angle. The effect of pressure cannot also be ignored. In short, by increasing both parameters of the pressure and aging time, the value of the contact angle increases and there is a direct correlation between the input and output variables.

\section{Conclusions}

Aging of the carbonate rock samples in fluorinated gases with commercial names of R134A and R404A at pressures above the critical pressure at a constant temperature of $70{ }^{\circ} \mathrm{C}$ and for different periods was performed to investigate the wettability alteration of the rock to the gasphilicity as well as the contact angle and imbibition tests to illustrate it. Accordingly:

- Both the R134A and R404A fluorinated gases can reduce the carbonate rock tendency to adsorb condensate and water, and the gasphilicity is produced by the aging of samples in these two.

- The gasphilic intensity at constant temperature depends on the pressure and the aging time, and the aging time plays a stronger role than the pressure due to the values obtained from the contact angle tests.

- The maximum contact angle obtained means more gasphilicity at the maximum pressure and duration of the experiments in both directions. Thus, for the R134A aged sections, the maximum contact angles in the presence of the air at a constant temperature of $70{ }^{\circ} \mathrm{C}$ and the supercritical pressure of $2000 \mathrm{psi}$ and after $72 \mathrm{~h}$ of aging

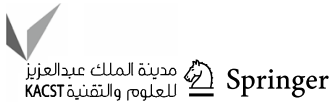


for the drops of water and condensates were 134.89 and $155.01^{\circ}$, respectively, and the maximum contact angles in the presence of the hydrocarbon gas at a constant temperature of $70{ }^{\circ} \mathrm{C}$ and the supercritical pressure of 2000 psi and after $72 \mathrm{~h}$ of aging for the drops of water and condensates were 120.97 and 136.91 degrees, respectively. These values for the aged sections in R404A for a drop of water and condensate in the presence of the air at the same conditions were 155.56 and 152.44 and in the presence of the hydrocarbon gas were 136.33 and 139.44 degrees, respectively.

- The results of imbibition experiments, in addition to the gasphilic verification of the aged porous media in R134A and R404A gases, compared with unaged plugs, show the newly obtained wettability of the gas-wet by imbibed water and condensate. As a result, the aged plug of R134A and immersed in a water and condensate environment imbibed 8.1 and $7.9 \%$ of the PV. These values for aged plug in R404A for water and condensate environment were 6.2 and $10.3 \% \mathrm{PV}$, respectively. However, unaged plugs with initial wettability by imbibed water and condensate were about 93 and $81 \% \mathrm{PV}$.

The study contains a series of initial tests to identify the ability of these two gases to produce gasphilic carbonate gas and does not focus much on the thermodynamic conditions of the gas condensate reservoir. Due to this important issue as well as the thermodynamic behavior of particular fluorinated gases, it is suggested that further studies on laboratory simulation of the thermodynamic conditions of these reservoirs take into account these properties in fluorinated gases. Besides, flood testing can be developed to obtain relative permeability.

\section{Compliance with ethical standards}

Conflict of interest The authors declare that they have no known competing financial interests or personal relationships that could have appeared to influence the work reported in this paper.

Open Access This article is licensed under a Creative Commons Attribution 4.0 International License, which permits use, sharing, adaptation, distribution and reproduction in any medium or format, as long as you give appropriate credit to the original author(s) and the source, provide a link to the Creative Commons licence, and indicate if changes were made. The images or other third party material in this article are included in the article's Creative Commons licence, unless indicated otherwise in a credit line to the material. If material is not included in the article's Creative Commons licence and your intended use is not permitted by statutory regulation or exceeds the permitted use, you will need to obtain permission directly from the copyright holder. To view a copy of this licence, visit http://creativecommons.org/licenses/by/4.0/.

\section{References}

Afidick D, Kaczorowski N, Bette S (1994) Production performance of a retrograde gas reservoir: a case study of the Arun field. In: SPE Asia pacific oil and gas conference. Society of Petroleum Engineers. Melbourne, Australia, SPE-28749-MS

Ahmadi M, Sharma MM, Pope G, Torres DE, McCulley CA, Linnemeyer $\mathrm{H}$ (2011) Chemical treatment to mitigate condensate and water blocking in gas wells in carbonate reservoirs. SPE Prod Oper 26(01):67-74. SPE-133591-PA

Ahmed T (2006) Reservoir engineering handbook, 3rd edn. Elsevier, Amsterdam

Al-Anazi HA, Walker JG, Pope GA, Sharma MM, Hackney DF (2003) A successful methanol treatment in a gas-condensate reservoir: field application. In: SPE production and operations symposium. Society of Petroleum Engineers. SPE-80901-PA

Al-Anazi HA, Xiao J, Al-Eidan AA, Buhidma IM, Ahmed MS, Al-Faifi M, Assiri WJ (2007) Gas productivity enhancement by wettability alteration of gas-condensate reservoirs. In: European formation damage conference, 30 May-1 June, Scheveningen, The Netherlands. Society of Petroleum Engineers. SPE-107493-MS

Ali M, Arif M, Sahito MF, Al-Anssari S, Keshavarz A, Barifcani A, Stalker L, Sarmadivaleh M, Iglauer S (2019) $\mathrm{CO}_{2}$-wettability of sandstones exposed to traces of organic acids: implications for $\mathrm{CO}_{2}$ geo-storage. Int J Greenh Gas Control 83:61-68

Ali M, Sahito MF, Jha NK, Memon S, Keshavarz A, Iglauer S, Saeedi A, Sarmadivaleh M (2020) Effect of nanofluid on $\mathrm{CO}_{2}$-wettability reversal of sandstone formation; implications for $\mathrm{CO}_{2}$ geo-storage. J Colloid Interface Sci 559:304-312

Al-Shammasi AA, D’Ambrosio A (2003) Approach to successful workovers in Karachaganak gas condensate field. In: SPE Latin American and Caribbean petroleum engineering conference. Conference, 27-30 April, Port-of-Spain, Trinidad and Tobago. Society of Petroleum Engineers. SPE-81084-MS

Aminnaji M, Fazeli H, Bahramian A, Gerami S, Ghojavand H (2015) Wettability alteration of reservoir rocks from liquid wetting to gas wetting using nanofluid. Transp Porous Media 109(1):201-216

Arabloo M, Shokrollahi A, Gharagheizi F, Mohammadi AH (2013) Toward a predictive model for estimating dew point pressure in gas condensate systems. Fuel Process Technol 116:317-324

Bang V, Yuan C, Pope G, Sharma M, Baran Jr J, Skildum J, Linnemeyer $\mathrm{H}$ (2008) Improving productivity of hydraulically fractured gas condensate wells by chemical treatment. In: Offshore technology conference, 5-8 May, Houston, Texas, USA. OTC-19599-MS

Bang VSS, Pope GA, Sharma MM, Baran Jr JR (2009) Development of a successful chemical treatment for gas wells with liquid blocking. In: SPE annual technical conference and exhibition, 4-7 October, New Orleans, Louisiana. SPE-124977-MS

Bartali R, Otyepka M, Pykal M, Lazar P, Micheli V, Gottardi G, Laidani $N$ (2017) Interaction of the helium, hydrogen, air, argon, and nitrogen bubbles with graphite surface in water. ACS Appl Mater Interfaces 9(20): 17517-17525

Chen SY, Kaufman Y, Kristiansen K, Seo D, Schrader AM, Alotaibi MB, Dobbs HA, Cadirov NA, Boles JR, Ayirala SC, Israelachvili JN (2017) Effects of salinity on oil recovery (the "Dilution Effect"): experimental and theoretical studies of crude oil/brine/ carbonate surface restructuring and associated physicochemical interactions. Energy Fuels 31(9):8925-8941

Dandekar AY (2013) Petroleum reservoir rock and fluid properties, 2nd edn. CRC Press, Boca Raton

Deng F, Luo XB, Ding L, Luo SL (2019) Application of nanomaterials and nanotechnology in the reutilization of metal ion from wastewater. In: Luo X, Deng F (eds) Nanomaterials for the removal 
of pollutants and resource reutilization. Elsevier, Amsterdam, pp $149-178$

Denney D (2009) Effect of salinity on wettability alteration of porous media from liquid-wetting to intermediate gas-wetting. J Pet Technol 61(10):51-52

Du L, Walker JG, Pope GA, Sharma MM, Wang P (2000) Use of solvents to improve the productivity of gas condensate wells. In: SPE annual technical conference and exhibition, 1-4 October, Dallas, Texas. SPE-62935-MS

Fahes MM, Firoozabadi A (2007) Wettability alteration to intermediate gas-wetting in gas-condensate reservoirs at high temperatures. SPE J 12(04):397-407. SPE-96184-PA

Fahimpour J, Jamiolahmady M (2015) Optimization of fluorinated wettability modifiers for gas/condensate carbonate reservoirs. SPE J 20(04):729-742. SPE-154522-PA

Fan L, Harris BW, Jamaluddin A, Kamath J, Mott R, Pope GA, Shandrygin A, Whitson $\mathrm{CH}$ (2005) Understanding gas-condensate reservoirs. Oilfield Rev 17(4):14-27

Gahrooei HRE, Ghazanfari MH (2017a) Application of a water based nanofluid for wettability alteration of sandstone reservoir rocks to preferentially gas wetting condition. J Mol Liq 232:351-360

Gahrooei HRE, Ghazanfari MH (2017b) Toward a hydrocarbonbased chemical for wettability alteration of reservoir rocks to gas wetting condition: implications to gas condensate reservoirs. J Mol Liq 248:100-111

Hinchman S, Barree R (1985) Productivity loss in gas condensate reservoirs. In: SPE annual technical conference and exhibition. Society of Petroleum Engineers. SPE-14203-MS

Hoseinpour SA, Madhi M, Norouzi H, Soulgani BS, Mohammadi AH (2019) Condensate blockage alleviation around gas-condensate producing wells using wettability alteration. J Nat Gas Sci Eng 62:214-223

Hoteit H (2013) Modeling diffusion and gas-oil mass transfer in fractured reservoirs. J Pet Sci Eng 105:1-17

Huhtamäki T, Tian X, Korhonen JT, Ras RH (2018) Surface-wetting characterization using contact-angle measurements. Nat Protoc 13(7):1521-1538

Imo-Jack O (2010) PVT characterization of a gas condensate reservoir and investigation of factors affecting deliverability. In: Nigeria annual international conference and exhibition. Society of Petroleum Engineers

Jin J, Wang Y, Wang K, Ren J, Bai B, Dai C (2016) The effect of fluorosurfactant-modified nano-silica on the gas-wetting alteration of sandstone in a $\mathrm{CH}_{4}$-liquid-core system. Fuel 178:163-171

Kamari A, Sattari M, Mohammadi AH, Ramjugernath D (2016) Rapid method for the estimation of dew point pressures in gas condensate reservoirs. J Taiwan Inst Chem Eng 60:258-266

Kaplan WD, Chatain D, Wynblatt P, Carter WC (2013) A review of wetting versus adsorption, complexions, and related phenomena: the rosetta stone of wetting. J Mater Sci 48(17):5681-5717

Karandish GR, Rahimpour MR, Sharifzadeh S, Dadkhah AA (2015) Wettability alteration in gas-condensate carbonate reservoir using anionic fluorinated treatment. Chem Eng Res Des 93:554-564

K1lıç M, Gönül E (2016) Adsorption characteristics evaluation of R134A and R404A on different adsorbents. Bulg Chem Commun 48:306-311

Kumar V, Pope GA, Sharma MM (2006) Improving the gas and condensate relative permeability using chemical treatments. In: SPE gas technology symposium, 15-17 May, Calgary, Alberta, Canada. Society of Petroleum Engineers. SPE-100529-MS

Lal RR (2003) Well testing in gas-condensate reservoirs. Stanford University. M.Sc. Thesis

Lee S, Chaverra M (1998) Modelling and interpretation of condensate banking for the near critical Cupiagua field. In: Paper SPE 49265 presented at the SPE annual technical conference and exhibition, New Orleans, Louisiana, 27-30 September. SPE-49265-MS

Li K, Firoozabadi A (2000) Experimental study of wettability alteration to preferential gas-wetting in porous media and its effects. SPE Reserv Eval Eng 3(02):139-149 (SPE-62515-PA)

Li K, Liu Y, Zheng H, Huang G, Li G (2011) Enhanced gas-condensate production by wettability alteration to gas wetness. J Pet Sci Eng 78(2):505-509

Li Y, Jiang G, Li L, Xu W, Yu Y, Zhang X, Xie S (2014) The effect of a novel gas-wetting reversal FC-1 on the condensate gas reservoir core. Pet Sci Technol 32(1):1-7

Linde Group (2015) Gases \& applications, 2015 edition, Linde Gases Division, Seitnerstrasse 70, D-82049 Pullach, Germany

Linert JG (1997) A new water-soluble fluoropolymer silanol and its application in stone and concrete protection. In: Paper presented at the 1997 Waterborne, high-solids, and powder coating symposium, February 5-7

Liu Y, Zheng H, Huang G, Li G, Li K (2006) Improving production in gas/condensate reservoirs by wettability alteration to gas wetness. In: SPE/DOE symposium on improved oil recovery, 22-26 April, Tulsa, Oklahoma, USA. Society of Petroleum Engineers. SPE-99739-MS

Manshad AK, Nowrouzi I, Mohammadi AH (2017a) Effects of water soluble ions on wettability alteration and contact angle in smart and carbonated smart water injection process in oil reservoirs. $\mathrm{J}$ Mol Liq 244:440-452

Manshad AK, Rezaei M, Moradi S, Nowrouzi I, Mohammadi AH (2017b) Wettability alteration and interfacial tension (IFT) reduction in enhanced oil recovery (EOR) process by ionic liquid flooding. J Mol Liq 248:153-162

Marhaendrajana T, Ridwan MG, Kamil MI, Permadi P (2018) Wettability alteration induced by surface roughening during low salinity waterflooding. J Eng Technol Sci 50(5):635-649

Milella A, Palumbo F, Favia P, Cicala G, d'Agostino R (2004) Continuous and modulated deposition of fluorocarbon films from c-C4F8 plasmas. Plasma Process Polym 1(2):164-170

Miller N (2010) Increasing well productivity in gas condensate wells in Qatar's North Field. Doctoral dissertation, Texas A \& M University

Mohammadi AH, Eslamimanesh A, Richon D (2012) Asphaltene precipitation in gas condensate system. In: James C (ed) Advances in chemistry research, vol 15. Taylor, Nova Science Publishers Inc., New York

Mousavi MA, Hassanajili S, Rahimpour MR (2013) Synthesis of fluorinated nano-silica and its application in wettability alteration near-wellbore region in gas condensate reservoirs. Appl Surf Sci 273:205-214

Najafi-Marghmaleki A, Tatar A, Barati-Harooni A, Choobineh MJ, Mohammadi AH (2016) GA-RBF model for prediction of dew point pressure in gas condensate reservoirs. J Mol Liq 223:979-986

Najafi-Marghmaleki A, Tatar A, Barati-Harooni A, Arabloo M, RafieeTaghanaki S, Mohammadi AH (2018) Reliable modeling of constant volume depletion (CVD) behaviors in gas condensate reservoirs. Fuel 231:146-156

Noh MH, Firoozabadi A (2008) Wettability alteration in gas-condensate reservoirs to mitigate well deliverability loss by water blocking. SPE Reserv Eval Eng 11(04):676-685. SPE-98375-PA

Nowrouzi I, Manshad AK, Mohammadi AH (2020a) Effects of $\mathrm{TiO}_{2}$, $\mathrm{MgO}$ and $\gamma-\mathrm{Al}_{2} \mathrm{O}_{3}$ nano-particles on wettability alteration and oil production under carbonated nano-fluid imbibition in carbonate oil reservoirs. Fuel 259:116110

Nowrouzi I, Manshad AK, Mohammadi AH (2020b) Evaluation of interfacial tension (IFT), oil swelling and oil production under imbibition of carbonated water in carbonate oil reservoirs. J Mol Liq 312:113455

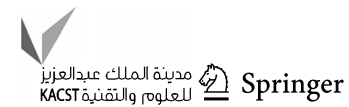


Nowrouzi I, Mohammadi AH, Manshad AK (2020c) Effect of a synthesized anionic fluorinated surfactant on wettability alteration for chemical treatment of near-wellbore zone in carbonate gas condensate reservoirs. Pet Sci. https://doi.org/10.1007/s1218 2-020-00446-w

Nowrouzi I, Mohammadi AH, Manshad AK (2020d) Water-oil interfacial tension (IFT) reduction and wettability alteration in surfactant flooding process using extracted saponin from Anabasis Setifera plant. J Pet Sci Eng 189:106901

Rahimzadeh A, Bazargan M, Darvishi R, Mohammadi AH (2016) Condensate blockage study in gas condensate reservoir. J Nat Gas Sci Eng 33:634-643

Rocke R-S, Sharma MM, Bang V, Ahmadi M, Linnemeyer HC (2008) Improving well productivity in gas condensate reservoirs via chemical treatment. In: Tobago gas technology conference. The University of Trindad and Tobago, Lowlands, Tobago, October $7-10$

Rogers W Jr, Sclar M (1932) A modification of the Freundlich adsorption isotherm. J Phys Chem 36(8):2284-2291

Rudzinski W, Everett DH (2012) Adsorption of gases on heterogeneous surfaces, 1st edn. Academic Press, Cambridge

Saboori R, Azin R, Osfouri S, Sabbaghi S, Bahramian A (2017) Synthesis of fluorine-doped silica-coating by fluorosilane nanofluid to ultrahydrophobic and ultraoleophobic surface. Mater Res Express 4(10): 105010

Saboori R, Azin R, Osfouri S, Sabbaghi S, Bahramian A (2018) Wettability alteration of carbonate rocks from strongly liquid-wetting to strongly gas-wetting by fluorine-doped silica coated by fluorosilane. J Dispers Sci Technol 39(6):767-776

Sakhaei Z, Azin R, Naghizadeh A, Osfouri S, Saboori R, Vahdani $\mathrm{H}$ (2018) Application of fluorinated nanofluid for production enhancement of a carbonate gas-condensate reservoir through wettability alteration. Mater Res Express 5(3):035008

Santoso RK, Rachmat S, Resha AH, Putra WDK, Hartowo H, Setiawati $\mathrm{O}$ (2016) An investigation of $\mathrm{Fe} 2 \mathrm{O} 3$ nanoparticles diffusion into oil for heat transfer optimisation on electromagnetic heating for well stimulation and EOR. In: SPE Asia Pacific oil \& gas conference and exhibition. Society of Petroleum Engineers. SPE-182152-MS

Santoso R, Torrealba V, Hoteit H (2020) Investigation of an improved polymer flooding scheme by compositionally-tuned slugs. Processes 8(2):197
Srinivasan S, McKinley GH, Cohen RE (2011) Assessing the accuracy of contact angle measurements for sessile drops on liquidrepellent surfaces. Langmuir 27(22):13582-13589

Tang GQ, Firoozabadi A (2000) Relative permeability modification in gas-liquid systems through wettability alteration to intermediate gas-wetting. In: SPE annual technical conference and exhibition, 1-4 October, Dallas, Texas. Society of Petroleum Engineers. SPE-62934-MS

Tang GQ, Firoozabadi A (2003) Wettability alteration to intermediate gas-wetting in porous media at elevated temperatures. Transp Porous Media 52(2):185-211

Torrealba VA, Hoteit H (2019) Improved polymer flooding injectivity and displacement by considering compositionally-tuned slugs. J Pet Sci Eng 178:14-26

Wang X, Indriati S, Valko PP, Economides MJ (2000) Production impairment and purpose-built design of hydraulic fractures in gas-condensate reservoirs. In: International oil and gas conference and exhibition in China, 7-10 November, Beijing, China. SPE-64749-MS

Wang Y, Jin J, Ma L, Li L, Zhao X (2015) Influence of wettability alteration to preferential gas-wetting on displacement efficiency at elevated temperatures. J Dispers Sci Technol 36(9):1274-1281

Wu S, Firoozabadi A (2010a) Permanent alteration of porous media wettability from liquid-wetting to intermediate gas-wetting. Transp Porous Media 85(1):189-213

Wu S, Firoozabadi A (2010b) Effect of salinity on wettability alteration to intermediate gas-wetting. SPE Reserv Eval Eng 13(02):228-245

Young T (1805) An essay on the cohesion of fluids. Philos Trans R Soc Lond 95:65-87

Zhang S, Jiang GC, Wang L, Qing W, Guo HT, Tang XG, Bai DG (2014) Wettability alteration to intermediate gas-wetting in lowpermeability gas-condensate reservoirs. J Pet Explor Prod Technol 4(3):301-308

Publisher's Note Springer Nature remains neutral with regard to jurisdictional claims in published maps and institutional affiliations. 